\title{
Effect of diabetes self-management education program on glycemic control in diabetic patients attending the family medicine outpatient clinic, Suez Canal University Hospital, Ismailia, Egypt
}

\author{
Reham Abo Emara*, Madeha Hamed, Mohamed Awad and Wael Zeid
}

\begin{abstract}
Background: Diabetes mellitus (DM) is a chronic disease with debilitating complications. Patients with diabetes are recommended to take various self-management decisions and carry out complex care activities. Diabetes selfmanagement education (DSME) and support help people with diabetes to take these decisions and activities to improve health outcomes. DSME may serve as the basis to minimize and avoid catastrophic diabetes-related complications and the resulting financial and personal costs associated with this disorder. We aimed to assess the effect of diabetes self-management education program on glycemic control on patients with diabetes. A quasiexperimental pre-post study was conducted at the family medicine clinic in Suez Canal University hospital, Ismailia, Egypt. A total of 116 patients with uncontrolled DM were recruited by a simple random technique after applying the inclusion and exclusion criteria. Participants were subjected to a 12-week health education program (1 session/ week). The sessions focused on areas of diabetes self-management based on the American Diabetes Association (ADA) guidelines. The glycosylated hemoglobin $(\mathrm{HbA1c})$ was assessed at baseline and again at the end of the program. Also, self-care activities were evaluated pre-post intervention using the Arabic version of the Summary of Diabetes Self-Care Activities (SDSCA) instrument which measured the activities related to diet, exercise, blood sugar testing, foot care, and medications.

Results: The mean age of participants was 47 years $( \pm 11.54)$, male patients represented $54 \%$. About two-thirds (67\%) were from urban areas and came from a middle socioeconomic level. About half of the participants (51.7\%) were diagnosed as diabetics for 5-10 years duration. More than half (52.7\%) were on combination therapy of insulin and oral antidiabetic drugs. After the intervention program, there was a statistically significant decrease in HbA1c level ( $p$ value $<0.001$ ), and 21\% of the participants reached the ADA treatment goal for HbA1c below 7 .
\end{abstract}

Conclusion: Appropriate DSME programs are practical and have a benefit to patients with diabetes.

Keywords: Diabetes mellitus, Self-management, Self-care

\footnotetext{
* Correspondence: rehamaboemara@gmail.com

Family Medicine Department, Faculty of Medicine, Suez Canal University, Kilo 4.5 Round Road, Ismailia 41522, Egypt
}

SpringerOpen (c) The Author(s). 2021 Open Access This article is licensed under a Creative Commons Attribution 4.0 International License, which permits use, sharing, adaptation, distribution and reproduction in any medium or format, as long as you give appropriate credit to the original author(s) and the source, provide a link to the Creative Commons licence, and indicate if changes were made. The images or other third party material in this article are included in the article's Creative Commons licence, unless indicated otherwise in a credit line to the material. If material is not included in the article's Creative Commons licence and your intended use is not permitted by statutory regulation or exceeds the permitted use, you will need to obtain permission directly from the copyright holder. To view a copy of this licence, visit http://creativecommons.org/licenses/by/4.0/. 


\section{Background}

Diabetes mellitus (DM) is a chronic metabolic disease caused by an interaction between genetic, immunological, and environmental factors and characterized by increased blood glucose due to either insulin deficiency, insulin resistance, or both [1]. According to the International Diabetes Federation (IDF), about $9 \%$ of adults from 20 to 79 years suffered from diabetes; moreover, about $50 \%$ of diabetic patients are undiagnosed. Diabetes mellitus is one of the most common causes of mortality and high health expenditure worldwide [2].

Patients with diabetes should perform certain self-care activities in order to control the progression of the disease [3]. These self-care activities include healthy eating, being physically active, blood sugar monitoring, medication adherence, good problem-solving skills, healthy coping skills, and risk-reduction behaviors. These seven behaviors can be correlated with good glycemic control, complication reduction, and quality of life improvement [4].

Though diabetes self-management (DSM) is considered the foundation of managing diabetes, there is a major awareness gap in Egypt about DSM [5]. Education about DSM will serve as the basis to establish and incorporate effective strategies aimed at minimizing and avoiding catastrophic diabetes-related complications and the resulting financial and personal costs associated with this disorder. This research therefore aimed at evaluating the effect of diabetes self-management education (DSME) program on glycated hemoglobin (HbA1C) as an important indicator for diabetic control.

\section{Methods}

\section{Study setting and design}

A quasi-experimental study was started on 120 patients with uncontrolled DM, from which 116 continued a 12 follow-up period. Two patients were lost in the followup, and two patients refused to continue the program. The sample size was calculated by using the following equation of the difference between two means: $n=2[(a$ $\left.+b)^{2} \times \sigma^{2}\right] /(\mu 1-\mu 2)^{2}$, where $n$ is the sample size in each group, $a$ is the value of standard normal distribution for type I error probability for the two-sided test $(0.05 / 2)=$ $1.96, b$ is the value of standard normal for the desired statistical power $(90 \%)=1.282, \sigma^{2}$ is the expected population variance $(\mathrm{SD})=(1.72)^{2}, \mu 1$ is the mean of diabetes empowerment scale (pretest) $=3.75$, and $\mu 2$ is the mean of diabetes empowerment scale (posttest) $=4.56[6,7]$. The sample was selected by a simple random sampling technique, from those who attended (the family medicine clinic in Suez Canal University hospital, Ismailia, Egypt), from June 2019 to December 2019. The study setting was chosen, because it provides preventive and curative services to patients with chronic diseases, including DM. Adult patients aged 18 years or more with uncontrolled DM (HbA1c more than 7) were included, out of which diabetic patients with a psychiatric disease or cognitive impairment interfering with treatment compliance, or pregnant women were excluded. This study was approved by the institutional ethics committee. Informed written consent was obtained from the participants. All procedures were performed in accordance with the 1964 Helsinki Declaration and its later amendments.

\section{Assessment}

The socioeconomic status was assessed at baseline, using a valid and reliable tool in Arabic evaluating domains related to education, culture, occupation, family, home sanitation, economic status, and health care, with a total score of 84 . The socioeconomic level was classified into very low, low, middle, and high levels depending on the quartiles of the score calculated [8].

Medical history including duration of diabetes, therapeutic regimen, other medical treatment, presence of comorbid diseases, and adherence to diet and medications was also assessed at baseline. A pilot test was conducted on 20 patients (not included in the main sample) to test the feasibility and understandability of the questions. The validity of this part was pre-determined by three experienced professors of family and community medicine.

The self-care activities were evaluated pre-post intervention using the Arabic version of the Summary of Diabetes Self-Care Activities (SDSCA) instrument which measured the activities related to diet, exercise, blood sugar testing, foot care, and medications. Response choices range between 0 and 7, representing a particular behavior in the past 7 days. For each subscale, a mean score is calculated. Higher scores indicate a more frequent performance of the self-care activity [9].

DM control was assessed by collecting blood samples to measure glycosylated hemoglobin (HbA1C) at baseline and then at the end of the intervention program. Blood samples were collected under standard infection control measures.

\section{Intervention}

The DSME intervention program included 12 weekly sessions held in the family medicine clinic in Suez Canal University hospital, Ismailia, Egypt. The first session was an orientation about the program, diabetes types, discussion of hyper/hypoglycemia signs, symptoms, and treatment. The participants were asked to share their feelings about the diagnosis of diabetes at the beginning of the first diabetes self-management session. The remaining eleven sessions included modules on healthy eating, being active, medications, glucose monitoring and complications, and symptoms management. At the end of each session, each participant took home activities aiming to reinforce on the information given and sharing their experience, success, and struggles next week. 


\section{Statistical analysis}

Data was analyzed using Statistical Package of Social Science (SPSS) version 21 for Windows software. Data was presented using descriptive statistics in the form of frequencies and percentages for qualitative variables, and means and standard deviations for quantitative variables. Comparison between pre-post results was performed using the Wilcoxon signed-rank test. Multivariable linear regression was assessed by the ANOVA test. Group differences were ascertained by the Kruskal-Wallis test and Mann-Whitney test. $p$ values less than 0.05 were considered statistically significant.

\section{Results}

The sociodemographic characteristics of the studied sample were calculated. The mean age of the participants was $47.09 \pm 11.54$ years. Males formed $54.3 \%$ of the participants whereas females formed $45.7 \%$ of the sample. Participants who can only read and write formed $21.6 \%$, while those who finished high school represented $22.4 \%$. More than two-thirds (69.8\%) had 5 members or more in their families, and more than half (55.2\%) of the participants depend on free governmental health services (Table 1). According to the scale of the total score, about two-thirds (67\%) of the participants were in the middle socioeconomic level.

Regarding the medical history, about half of the participants (51.7\%) were diagnosed as diabetics for 5-10 years duration. About $52.7 \%$ used combined oral anti-

Table 1 Baseline socioeconomic characteristics of the participants $(n=116)$

\begin{tabular}{ll}
\hline Variables & $\boldsymbol{N}(\%)$ \\
\hline Age (years), mean \pm SD & $47.09 \pm 11.54$ \\
Gender & $63(54.3)$ \\
Male & $53(45.7)$ \\
Female & \\
Education & $20(17.2)$ \\
$\quad$ Illiterate & $25(21.6)$ \\
Read and write & $17(14.7)$ \\
Primary school & $4(3.4)$ \\
Preparatory school & $26(22.4)$ \\
Secondary & $18(15.5)$ \\
Intermediate & $6(5.2)$ \\
University & \\
Number of family members & $81(69.8)$ \\
$\geq 5$ members & $35(30.2)$ \\
$<5$ members & \\
Usual source of health care & $64(55.2)$ \\
Free governmental health services & $52(44.8)$ \\
More than one source &
\end{tabular}

Data are presented as mean \pm SD or frequency (\%) hyperglycemic and insulin to control their illness. Neurological disorders, dyslipidemia, and hypertension were found to be the top three co-morbidities with diabetes. Table 2 shows that patients' HbAlc was significantly higher among patients on herbal medications $(p=$ $0.005)$ and among those who received medical treatments for other diseases $(p=0.005)$.

Figure 1 shows that the self-management education program had a statistically significant reduction of HbA1C among participants of our study $(8.76 \pm 1.02$ before the intervention vs $8.05 \pm 0.89$ after the intervention) $(p<0.01)$.

Multivariable linear regression analysis was used to assess the predictors of $\mathrm{HbA} 1 \mathrm{c}$ among the study sample. $R^{2}=15 \%$, where $15 \%$ of the variability HbA1c among the study sample can be explained by this linear model

Table 2 Association between medical characteristics of the patients and $\mathrm{HbA} 1 \mathrm{c}$ levels

\begin{tabular}{|c|c|c|}
\hline Variables & HbA1c (mean \pm SD) & $p$-value \\
\hline \multicolumn{3}{|l|}{ Duration of DM } \\
\hline$<5$ years & $7.93 \pm 0.74$ & $0.32^{\mathrm{a}}$ \\
\hline $5-10$ years & $8.15 \pm 0.87$ & \\
\hline$>10$ years & $8 \pm 1.22$ & \\
\hline \multicolumn{3}{|l|}{ Daily drug regimen } \\
\hline Oral anti-hyperglycemic drugs only & $8.24 \pm 1$ & $0.10^{\mathrm{a}}$ \\
\hline Insulin only & $7.50 \pm 0.3$ & \\
\hline Combined & $7.88 \pm 0.79$ & \\
\hline \multicolumn{3}{|l|}{ Herbal treatment usage } \\
\hline No & $8.02 \pm 0.86$ & $0.005^{\mathrm{b}}$ \\
\hline Yes & $10 \pm 0.02$ & \\
\hline \multicolumn{3}{|l|}{ Supplementation usage } \\
\hline No & $8.18 \pm 1.03$ & $0.79^{b}$ \\
\hline Yes & $8.01 \pm 0.84$ & \\
\hline \multicolumn{3}{|l|}{ Medical treatment for other diseases } \\
\hline No & $7.82 \pm 0.73$ & $0.005^{\mathrm{b}}$ \\
\hline Yes & $8.21 \pm 0.95$ & \\
\hline \multicolumn{3}{|l|}{ Co-morbidities } \\
\hline Absent & $7.69 \pm 0.84$ & $0.001^{b}$ \\
\hline Present & $8.17 \pm 0.88$ & \\
\hline \multicolumn{3}{|l|}{ Adherence to diet } \\
\hline No & $8.43 \pm 1.01$ & $0.17^{\mathrm{b}}$ \\
\hline Yes & $7.98 \pm 0.85$ & \\
\hline \multicolumn{3}{|l|}{ Adherence to treatment } \\
\hline No & $8.7 \pm 0.92$ & $0.19^{\mathrm{b}}$ \\
\hline Yes & $8.03 \pm 0.88$ & \\
\hline
\end{tabular}




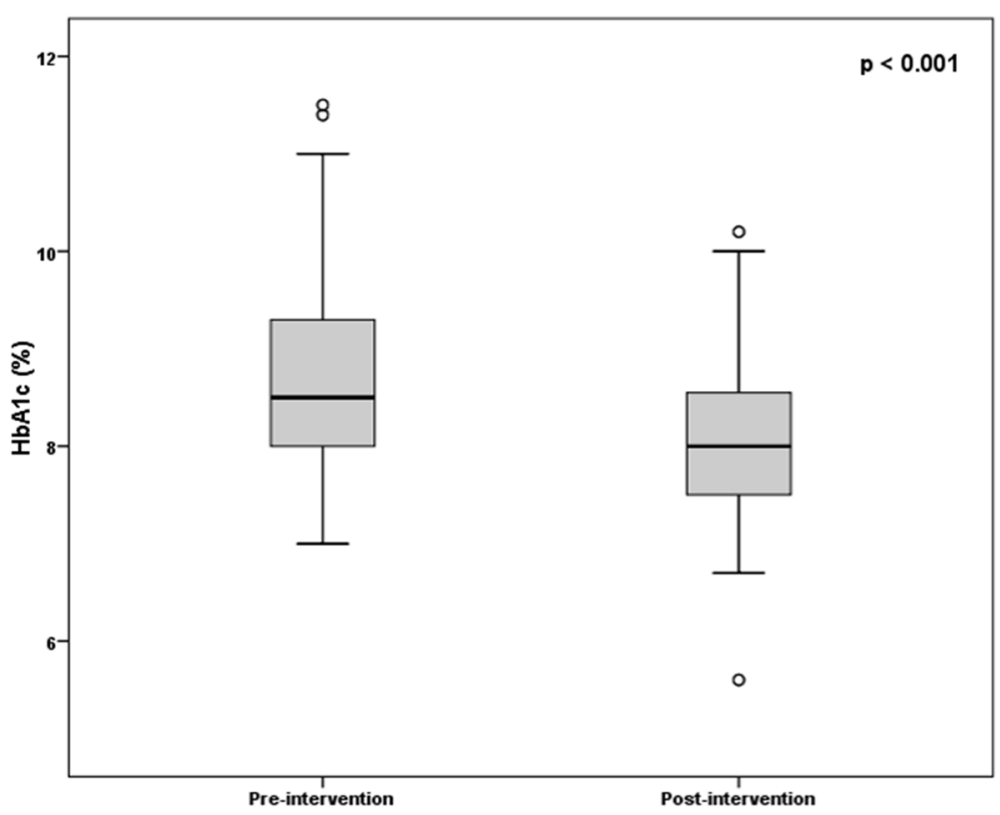

Fig. 1 Pre- and post-intervention levels of $\mathrm{HbA} 1 \mathrm{c}$

(Table 3). We found that for every one point increase in the SDSCA score, there is a decrease by 0.249 units in the HbA1c of the diabetic patients $(p=0.014)$. Moreover, there is an increase by 0.243 units in the HbA1c of the diabetic patients who are on herbal medications compared to those who do not administer them $(p=0.005)$.

\section{Discussion}

Poor glycemic regulation was closely linked to increased morbidity and mortality risk for diabetes. More significantly, anti-diabetes drugs alone, given their accessibility and proven effectiveness in many patients with diabetes, were unable to achieve optimal glycemic regulation in the absence of the information and behaviors of good patients [10].
This quasi-experimental study was conducted at the family medicine clinic in Suez Canal University hospital, Ismailia, Egypt. One hundred sixteen uncontrolled patients with diabetes were enrolled. Their glycemic control, as noted by Hb1Ac, was assessed, and then, the enrolled patients were subjected to a DSME program which consisted of twelve weekly sessions based on the American Diabetes Association (ADA) guidelines. At the end of the program, Hb1Ac levels were reassessed and compared to the baseline scores. We found that our patients had a modest but significant decrease in their HbA1c level after the 12-week interventional program $(8.76 \pm 1.02$ vs $8.05 \pm 0.89, p<0.01)$.

Also, this finding is consistent with the recent Egyptian study that reported a significant decrease in HbAlc

Table 3 Multivariable linear regression analysis of determinants of patients' HbA1c levels

\begin{tabular}{|c|c|c|c|c|c|}
\hline \multirow[t]{2}{*}{ Predictors } & \multicolumn{2}{|c|}{ Unstandardized coefficients } & \multirow{2}{*}{$\begin{array}{l}\text { Standardized } \\
\text { coefficients, beta }\end{array}$} & \multirow[t]{2}{*}{$95 \% \mathrm{Cl}$} & \multirow[t]{2}{*}{$p$ value } \\
\hline & $B$ & Std. error & & & \\
\hline Constant & 9.227 & 0.631 & & & $<0.001^{*}$ \\
\hline \multicolumn{6}{|l|}{ Chronic illness } \\
\hline Yes vs no $(R)$ & 0.267 & 0.249 & 0.129 & -0.226 to 0.759 & 0.286 \\
\hline \multicolumn{6}{|c|}{ Medical treatment for other diseases } \\
\hline Yes vs no $(R)$ & -0.012 & 0.227 & -0.007 & -0.462 to 0.437 & 0.957 \\
\hline \multicolumn{6}{|l|}{ Herbals usage } \\
\hline Yes vs no $(R)$ & 1.694 & 0.592 & 0.249 & 0.521 to 2.867 & $0.005^{*}$ \\
\hline Total SDSCA post & -0.041 & 0.016 & -0.243 & -0.073 to -0.009 & $0.014^{*}$ \\
\hline
\end{tabular}

ANOVA $<0.001$

$R^{2}=0.015$

*Statistical significance at $p<0.05$ 
among type 2 diabetic patients who received a lifestyle education in the form of 48 weekly sessions over a 1-year period (HbA1c mean level 11.3 to 8.4, $p<0.001$ ) [5]. Similarly, another study in Taiwan indicated that a 6-month health coaching by a professional coach reduced HbA1c in type 2 diabetic patients by $0.68 \%$ [11].

Similar results were also reported by a systematic review of six studies comparing individual education to usual care over a 12-18-month period [12]. Another large multicenter randomized control clinical trial, the DESMOND trial, recruited 824 newly diagnosed type 2 diabetic patients from the UK. The trial reported that a structured group education program caused significant improvements in weight loss, smoking cessation, and patients' beliefs about the illness. On the other hand, and even though the program resulted in a $1.49 \%$ decrease in patients' HbA1c 12 months after diagnosis, this reduction was not significant. However, the educational content within this trial was only delivered for $6 \mathrm{~h}$ during the first 2 days of the study [13].

Nevertheless, two other systematic reviews, which included over one hundred randomized control experiments in each study, found a substantial improvement of HbA1c in studies with a contact time approaching $10 \mathrm{~h}$ [14]. Thus, contact hours and frequency of the applied instructional content are considered to be very important determinants of the efficacy of DSME programs [15].

In addition, patients with no related chronic conditions reported significantly lower HbA1c $(p=0.001)$. Glycated concentration of hemoglobin can be impaired by a number of factors related to development, hematology, and disease. In addition, no diabetic patients with chronic kidney disease had elevated levels of HbA1c. In addition, factors associated with higher erythropoiesis rates have been reported to be able to lower levels of HbA1c, such as iron and vitamin B 12 supplements [16].

In the current study, patients' summary of diabetes self-care activity (SDSCA) scores were found significantly higher among patients using supplement drugs $(p$ $=0.012$ ), those who were adherent to a healthy diet ( $p=$ 0.02 ), and those without any other associated chronic illnesses $(p<0.001)$. We postulated that these patients, who are already embracing a healthy lifestyle, will be more willing to achieve better self-care scores.

More importantly, we found a significant negative correlation between the total SDSCA score and HbA1c after the implantation of a12-week diabetes self-management program. As a matter of fact, there was a 0.249 -unit decrease in the HbA1c for every one point increase in the SDSCA score $(p=0.014)$.

\section{Limitations of the study}

This study had some limitations that need to be mentioned. First, the study was conducted in only one setting, and therefore, the reported findings are not representative and cannot be generalized to the whole Egyptian community. Also, potential confounding factors affecting the learning process, such as patients' motivation, attitude, emotional barriers especially for newly diagnosed patients, family, and social support, were also not meticulously controlled while assessing the effect of the interventional program.

\section{Conclusion}

DSME programs that have a benefit on glycemic control of diabetic patients consequently may prevent the onset and the progression of diabetic complications. Thus, future research is also needed to identify the best approach to DSME and to develop a standardized curriculum.

\section{Abbreviations \\ ADA: American Diabetes Association; ANOVA: Analysis of variance; DESMOND: Diabetes Education and Self-Management for Ongoing and Newly Diagnosed; DM: Diabetes mellitus; DSME: Diabetes self-management education; HbA1C: Glycosylated hemoglobin; IDF: International Diabetes Federation; SDSCA: Summary of Diabetes Self-Care Activities; SPSS: Statistical Package of Social Science}

\section{Acknowledgements \\ The authors would like to acknowledge all the participants for their cooperation.}

\section{Authors' contributions}

This work was carried out in collaboration between all authors. MH was responsible for choosing the tool of the study. RAE and WZ designed the study, wrote the manuscript, and were involved in the subject selections and data collection. MA was responsible for the statistical analysis and revised the final manuscript. All authors read and approved the final manuscript.

\section{Funding}

No fund received

\section{Availability of data and materials}

The datasets generated during this study are available from the corresponding author on reasonable request.

\section{Declaration}

Ethics approval and consent to participate

This study was approved by the ethics committee of the Faculty of Medicine, Suez Canal University, with approval number [3443 /2018]. Informed written consent was obtained from participants. All procedures were performed in accordance with the 1964 Helsinki Declaration and its later amendments.

\section{Consent for publication}

Not applicable

\section{Competing interests}

The authors declare that they have no competing interests.

Received: 7 June 2021 Accepted: 11 July 2021

Published online: 15 September 2021

\section{References}

1. American Diabetes Association (2021) Diagnosis and classification of diabetes mellitus. Standards of medical care in diabetes-2021. Diabetes Care 44(Supplement 1):S15-S33 https://doi.org/10.2337/dc21-S002

2. International Diabetes Federation. IDF Diabetes Atlas (2020). 9th Edition, International Diabetes Federation. available at: https://www.idf.org/search. 
html?searchword=prevalence\&ordering=newest\&searchphrase=all\&limit= 100.(Accessed date 3/3/2020).

3. Funnell MM, Brown TL, Childs BP, Haas LB, Hosey GM, Jensen B, Maryniuk M, Peyrot M, Piette JD, Reader D, Siminerio LM, Weinger K, Weiss MA (2011) National Standards for diabetes self-management education. Diabetes Care 34(Suppl 1):S89-S96. https://doi.org/10.2337/dc11-S089

4. Beck J, Greenwood DA, Blanton L, Bollinger ST, Butcher MK, Condon JE, Cypress M, Faulkner P, Fischl AH, Francis T, Kolb LE, Lavin-Tompkins JM, MacLeod J, Maryniuk M, Mensing C, Orzeck EA, Pope DD, Pulizzi JL, Reed AA, Rhinehart AS, Siminerio L, Wang J (2017) National standards for diabetes self-management education and support. Diabetes Spectr. 30(4):301-314. https://doi.org/10.2337/ds17-0067

5. Metwally AM, Soliman M, Abdelmohsen AM, Kandeel WA, Saber M, Elmosalami DM, Asem N, Fathy AM (2019) Effect of counteracting lifestyle barriers through health education in Egyptian type 2 diabetic patients. Open Access Maced J Med Sci. 7(17):2886-2894. https://doi.org/10.3889/oa mjms.2019.624

6. Goode P (2017) The effect of a diabetes selfmanagement program for African Americans in a faith-based setting (pilot study). Diabetes Manag. 7(2):223-233

7. Noordzij M, Tripepi G, Dekker FW, Zoccali C, Tanck MW, Jager KJ (2010) Sample size calculations: basic principles and common pitfalls. Nephrol Dial Transplant 25:1388-1393 Erratum in: Nephrol Dial Transplant 2010;25:3461-2

8. El-Gilany A, El-Wehady A, El-Wasify M (2012) Updating and validation of the socioeconomic status scale for health research in Egypt. East Mediterr Health J 18(9):962-968. https://doi.org/10.26719/2012.18.9.962

9. AlJohani KA, Kendall GE, Snider PD (2016) Psychometric Evaluation of the Summary of Diabetes Self-Care Activities-Arabic (SDSCA-Arabic): translation and analysis process. J Transcult Nurs. 27(1):65-72. https://doi.org/10.1177/1 043659614526255

10. Gathu CW, Shabani J, Kunyiha N, Ratansi R (2018). Effect of diabetes selfmanagement education on glycaemic control among type 2 diabetic patients at a family medicine clinic in Kenya: a randomised controlled trial. Afr J Prim Health Care Fam Med. 10(1):e1-e9. Published 2018 Nov 19. doi: https://doi.org/10.4102/phcfm.v10i1.1762

11. Chen RY, Huang LC, Su CT, Chang YT, Chu CL, Chang CL, Lin CL (2019) Effectiveness of short-term health coaching on diabetes control and selfmanagement efficacy: a quasi-experimental trial. Front Public Health. 7:314 https://doi.org/10.3389/fpubh.2019.00314

12. Duke SA, Colagiuri S, Colagiuri R (2009) Individual patient education for people with type 2 diabetes mellitus. Cochrane. Database Syst Rev (1): CD005268. https://doi.org/10.1002/14651858.CD005268.pub2

13. Davies MJ, Heller S, Skinner TC, et al (2008). "Effectiveness of the diabetes education and self management for ongoing and newly diagnosed (DESMOND) programme for people with newly diagnosed type 2 diabetes: cluster randomised controlled trial". BMJ (Clinical research ed.) vol. 336,7642: 491-5. doi:https://doi.org/10.1136/bmj.39474.922025.BE

14. Chrvala CA, Sherr D, Lipman RD (2016) Diabetes self-management education for adults with type 2 diabetes mellitus: a systematic review of the effect on glycemic control. Patient Educ Couns. 99(6):926-943. https:// doi.org/10.1016/j.pec.2015.11.003

15. Pillay J, Armstrong MJ, Butalia S, Donovan LE, Sigal RJ, Chordiya P, Dhakal S, Vandermeer B, Hartling L, Nuspl M, Featherstone R, Dryden DM (2015) Behavioral programs for type 1 diabetes mellitus: a systematic review and meta-analysis. Ann Intern Med. 163(11):836-847. https://doi.org/10.7326/M1 5-1399

16. Ikeda M, Shimazawa R (2019) Challenges to hemoglobin A1c as a therapeutic target for type 2 diabetes mellitus. J Gen Fam Med. 20(4):129-138. https://doi.org/10.1002/jgf2.244

\section{Publisher's Note}

Springer Nature remains neutral with regard to jurisdictional claims in published maps and institutional affiliations.

\section{Submit your manuscript to a SpringerOpen ${ }^{\circ}$ journal and benefit from:}

- Convenient online submission

- Rigorous peer review

- Open access: articles freely available online

- High visibility within the field

- Retaining the copyright to your article

Submit your next manuscript at $\boldsymbol{\nabla}$ springeropen.com 